\title{
Soil geohazard mapping for improved asset management of UK local roads
}

\author{
O. G. Pritchard, S. H. Hallett, and T. S. Farewell \\ School of Energy, Environment and Agrifood, Cranfield University, Cranfield, UK \\ Correspondence to: S. H. Hallett (s.hallett@cranfield.ac.uk)
}

Received: 2 April 2015 - Published in Nat. Hazards Earth Syst. Sci. Discuss.: 8 May 2015

Revised: 1 September 2015 - Accepted: 7 September 2015 - Published: 18 September 2015

\begin{abstract}
Unclassified roads comprise $60 \%$ of the road network in the United Kingdom (UK). The resilience of this locally important network is declining. It is considered by the Institution of Civil Engineers to be "at risk" and is ranked 26th in the world. Many factors contribute to the degradation and ultimate failure of particular road sections. However, several UK local authorities have identified that in drought conditions, road sections founded upon shrink-swell susceptible clay soils undergo significant deterioration compared with sections on non-susceptible soils. This arises from the local road network having little, if any, structural foundations. Consequently, droughts in East Anglia have resulted in millions of pounds of damage, leading authorities to seek emergency governmental funding.

This paper assesses the use of soil-related geohazard assessments in providing soil-informed maintenance strategies for the asset management of the locally important road network of the UK. A case study draws upon the UK administrative county of Lincolnshire, where road assessment data have been analysed against mapped clay-subsidence risk. This reveals a statistically significant relationship between road condition and susceptible clay soils. Furthermore, incorporation of UKCP09 future climate projections within the geohazard models has highlighted roads likely to be at future risk of clay-related subsidence.
\end{abstract}

\section{Introduction}

Minor, or non-strategic, roads which are owned and managed by local authorities represent $98 \%$ of the overall network in the United Kingdom (UK) (Defra, 2013). As a subclass, the unclassified road network represents $60 \%$ of this minor net- work (DfT, 2011) supporting local communities, society and the wider economy.

The Institution of Civil Engineers regards one-third of the UK's road network to be in urgent need of maintenance, stating that immediate action required to improve road conditions is its top priority (ICE, 2014). A number of factors can lead to road deterioration, including (but not restricted to) traffic volume, road works, poor construction or reinstatement after repair of buried infrastructure, cold weather, tarmacadam oxidation and underlying ground conditions. Several UK local authorities have argued that during drought conditions, changing moisture contents in underlying soils, in particular those clay soils prone to volumetric shrinking and swelling, have resulted in considerable structural damage to their highway networks (Table 1). Highway assets themselves exacerbate developing drought conditions by prohibiting the permeation of water into the underlying soils (Harrison et al., 2012).

A number of soil-related ground movements impact on UK highway networks, including clay shrinkage and swelling, sand washout, compression of soft soils and peat shrinkage (Pritchard et al., 2014). The county of Lincolnshire reported the largest impact of drought conditions on its highways in 2003 (Table 1), indicating that it is particularly prone to ground movement due to the county's abundance of shrink-swell (or expansive) susceptible clay soils. As clayrelated shrink-swell is the dominant form of ground movement in the UK, this paper examines the impact of clayrelated shrink-swell on road infrastructure.

Road damage resulting from expansive clay soils is reported to be problematic for a number of countries' highway networks, including the USA, Israel, India, South Africa, Sudan, Saudi Arabia, Nigeria, Australia and Algeria (Puppala 
Table 1. Drought damage to roads in 2003 (data sourced from Wilway et al., 2008).

\begin{tabular}{lr}
\hline Authority & $\begin{array}{r}\text { Reported drought } \\
\text { damage }(£ 000)\end{array}$ \\
\hline Lincolnshire & 7397 \\
Essex & 5614 \\
East Sussex & 5568 \\
Kent & 4167 \\
Cambridgeshire & 3522 \\
Hampshire & 3030 \\
Peterborough & 2400 \\
West Sussex & 2221 \\
Isle of Wight & 1500 \\
Wiltshire & 1302 \\
Buckinghamshire & 1200 \\
Surrey & 1000 \\
Suffolk & 750 \\
Norfolk & 650 \\
Bedfordshire & 300 \\
\hline Total & 40621 \\
\hline
\end{tabular}

et al., 2011; Abam et al., 2000; Alexander and Maxwell, 1996; Dafalla and Shamrani, 2011; Zumrawi, 2015). Tailor et al. (2011) argue that expansive soils are one of the most problematic foundation materials used in many of the countries identified above, often leading to annual replacement and maintenance costs running into the millions (US) (Sapkopta et al., 1997). Longitudinal cracking is the predominant mechanism of road failure recorded in the majority of studies (Puppala et al., 2011). Cracking of the road surface can often lead to a "vicious cycle" of successive shrink-swell episodes within the substrate, resulting in rapid deterioration of road surfaces and in the worst-case scenario car accidents and fatalities (Jegede, 2000). Wanyan et al. (2015), reporting on a Texas road survey, found that substrate moisture fluctuations represent the main perceived reason for longitudinal cracking of road surfaces, further exacerbated by poor drainage (Zumrawi, 2015).

Soil surveys, which classify the uppermost layer ( 0 to $1.2 \mathrm{~m}$ ) of the earth's surface, provide an understanding of soil properties and their spatial distribution. However, despite the intimate link between the soil and the infrastructure it supports, the application of soil surveys in highway asset management has seldom been undertaken within the UK. Elsewhere this is not the case, including in the USA (Bauer, 1973; Santi and Martens, 2003; Allemeier, 1974; Lee and Griffiths, 1987; Beatty and Bouma, 1973), Netherlands (Westerveld and Van Den Hurk, 1973) and Australia (Murtha and Reid, 1976; Biggs and Mahony, 2004). Whereas it is recognised that soil surveys have an established role (Hartnup and Jarvis, 1979), the UK still tends to look only to deeper geological maps for indications of surface movements.
Highway engineers and asset managers often have a civil engineering background, and many posses only general knowledge of earth sciences, geology and geotechnics. Clear spatial information which describes the risk of hazardous ground conditions, without the need for geological interpretation, is therefore potentially of great benefit to practicing engineers (Royse, 2011). Thematic soil-related geohazard maps, derived through reinterpretation of traditional soil maps and fusion with meteorological data, can provide decision makers with a clear view of the potential hazards affecting their assets.

This paper aims to demonstrate how soil-related geohazard assessments can serve within a decision support tool in the asset management of local highways. Many tangible associations have been posited with regard to the impact of geology and soils on road condition (Willway et al., 2008), especially in light of climatic change. However, quantitative analyses are currently lacking, providing this study with its novel approach.

To achieve this aim, empirical road condition data provided by Lincolnshire County Council (LCC) have been intersected spatially with an existing soil-related geohazard model to understand the statistical and spatial relationship between the two data sets. Furthermore, we investigate the use of UKCP09 climate projections to understand future clay-related subsidence risk in Lincolnshire. Subsequently, suggestions and recommendations resulting from the use of this approach for planned operational maintenance in Lincolnshire are described. Finally, we consider how this can form a framework for other local authorities to follow, both in the UK and internationally.

\section{Lincolnshire study area}

\subsection{Climatic, topographical and geological setting}

The administrative county of Lincolnshire is situated in mideastern England, spanning from the Humber Estuary in the north to the Wash in the south of the county (Fig. 1). As a result of its flat, fertile lands, a large area of the county is devoted to high-intensity agriculture. The county's relief is predominantly low lying $(0-50 \mathrm{~m}$ above sea level) excepting the Lincolnshire Wolds in the central-northern area of the county: a chalk outcrop, where heights range between 50 and $200 \mathrm{~m}$ above sea level.

This area of eastern England has a relatively mild, temperate climate. Annual rainfall is relatively low; for example in Lincoln it is $577 \mathrm{~mm}$. Consequently, it is one of the driest areas in the country (Hough and Jones, 1997). This low rainfall, coupled with high evapotranspiration rates, contributes to some of the highest soil moisture deficits (driest soils) in the UK in an average year (Hodge et al., 1984; Robson, 1990). 


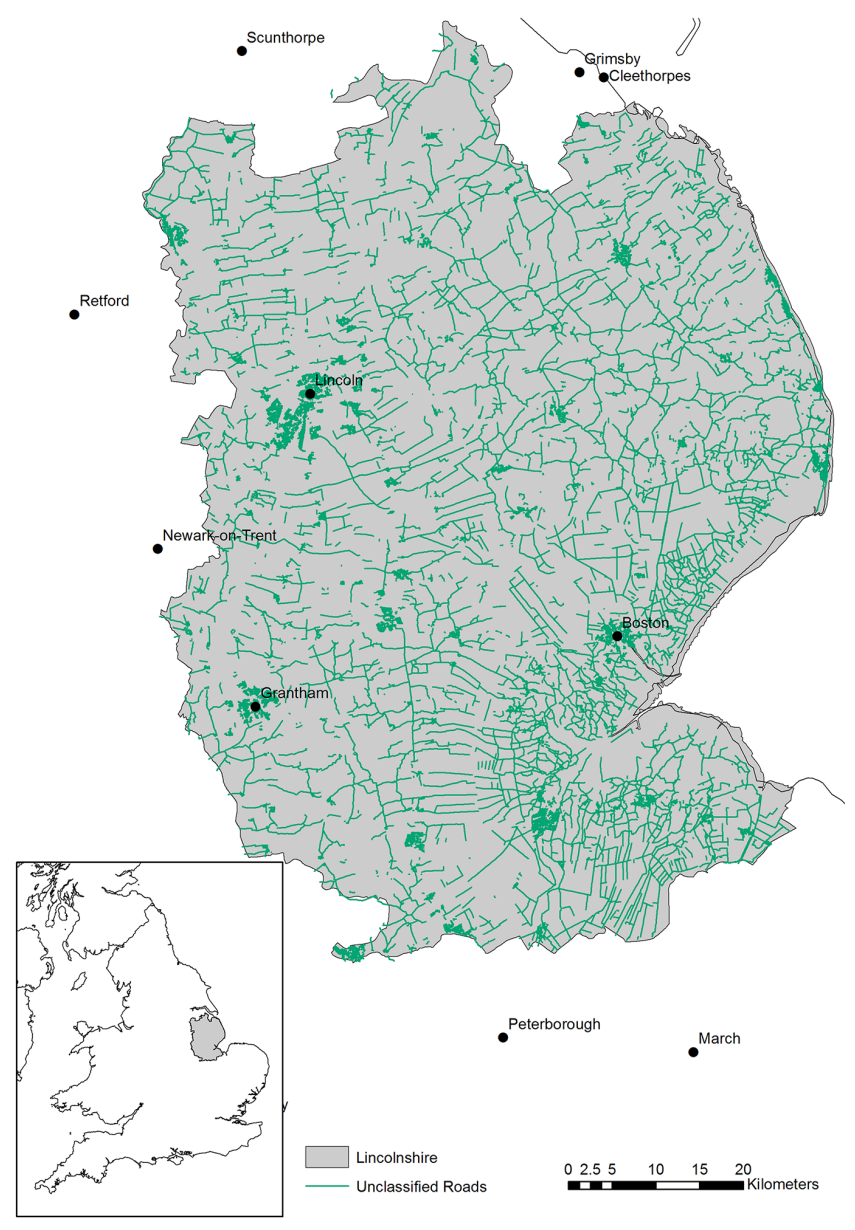

Figure 1. Lincolnshire location map and the distribution of unclassified roads.

The superficial geology and subsequently the soil parent material of Lincolnshire is predominantly derived from Pleistocene and more recent deposits (Hodge et al., 1984). The influence of previous glaciations and regressions and transgressions of the North Sea around the Wash have led to extensive deposits of silts, clays and the formation of peat material (Chatwin, 1961). Marine and riverine alluvium and glacial till represent a large proportion of the deposits, with glaciofluvial deposits dominating the Lincolnshire Wolds. As a result, Lincolnshire contains a broad range of soil types, encompassing 73 soil associations (Cranfield University, 2015). Further details of soil types and their distribution in Lincolnshire can be found in Hodge et al. (1984).

Industrial drainage in the Fenlands of Lincolnshire since the 1600s have caused such extensive peat wastage that previously underlying clays and silts are now exposed at the ground surface. Substantial thicknesses of peat are therefore now confined to the edge of the fens or to areas remaining undrained (Hodge et al., 1984). In 1985 it was recorded that only $16 \%\left(240 \mathrm{~km}^{2}\right)$ of the pre-drained peatland remained (Burton and Hodgson, 1987). The presence of large
Table 2. Road classification in terms of length and percentage of network in Lincolnshire.

\begin{tabular}{llrr}
\hline $\begin{array}{l}\text { LCC } \\
\text { hierarchy }\end{array}$ & $\begin{array}{l}\text { Road class } \\
(\mathrm{DfT})\end{array}$ & $\begin{array}{r}\text { Length } \\
(\mathrm{km})\end{array}$ & Percentage \\
\hline 1 & A (principal) & 888 & 10 \\
2 & A, (some) B & 560 & 6 \\
3 & B, (some) C & 1458 & 16 \\
4 and 5 & C, all unclassified & 5808 & 66 \\
\hline
\end{tabular}

areas of predominantly clay soils and their susceptibility to volumetric shrinkage, combined with high soil moisture deficits, means that Lincolnshire is particularly affected by clay-related subsidence.

\subsection{Unclassified road distribution}

This paper considers the unclassified road network of Lincolnshire (Fig. 1), representing $66 \%$ of the county's highways (Table 2), $85 \%$ of these roads being in rural areas. Unclassified roads are defined by the Department for Transport (DfT) as local roads intended for local traffic (DfT, 2012).

The majority of unclassified highways in Lincolnshire, as with many other UK counties, are deemed to be evolved. Evolved roads have not been designed to modern engineering standards and have instead evolved from historic or even ancient roads, even dating in some specific instances to the Roman and Bronze Age eras (Astbury, 1958).

The Coarse Visual Inspection (CVI) is a nationally defined standard of assessing road defects and is principally used on the UK's minor road networks. Further technical information regarding this survey can be found in Wallis (2009). CVI surveys revealed that Lincolnshire's unclassified road network has been subjected to severe drought-related subsidence, particularly during 2003 (Table 1) (M. Coates, personal communication, 2013). Moreover, during the 2010-2011 period, approximately 154 road sections were highlighted by the CVI survey as having been damaged as a direct result of drought conditions realising the shrinkage potential of clay rich soils (Fig. 2). It is likely that subsequent wetting events over winter months exacerbated road damage through swelling of clay soils, as reported in other studies (e.g. Puppala et al., 2011). These 2 event years led LCC to place a bid to central government for additional emergency road funding.

LCC highlights several safety hazards arising from soilrelated drought damaged roads, which are often unclassified and have speed limits of up to $60 \mathrm{mph}$ (miles per hour). Specific risks include

- increased deterioration of the longitudinal profile of roads, requiring drivers to reduce speeds below those that would normally be appropriate for the width and alignment of the road; 


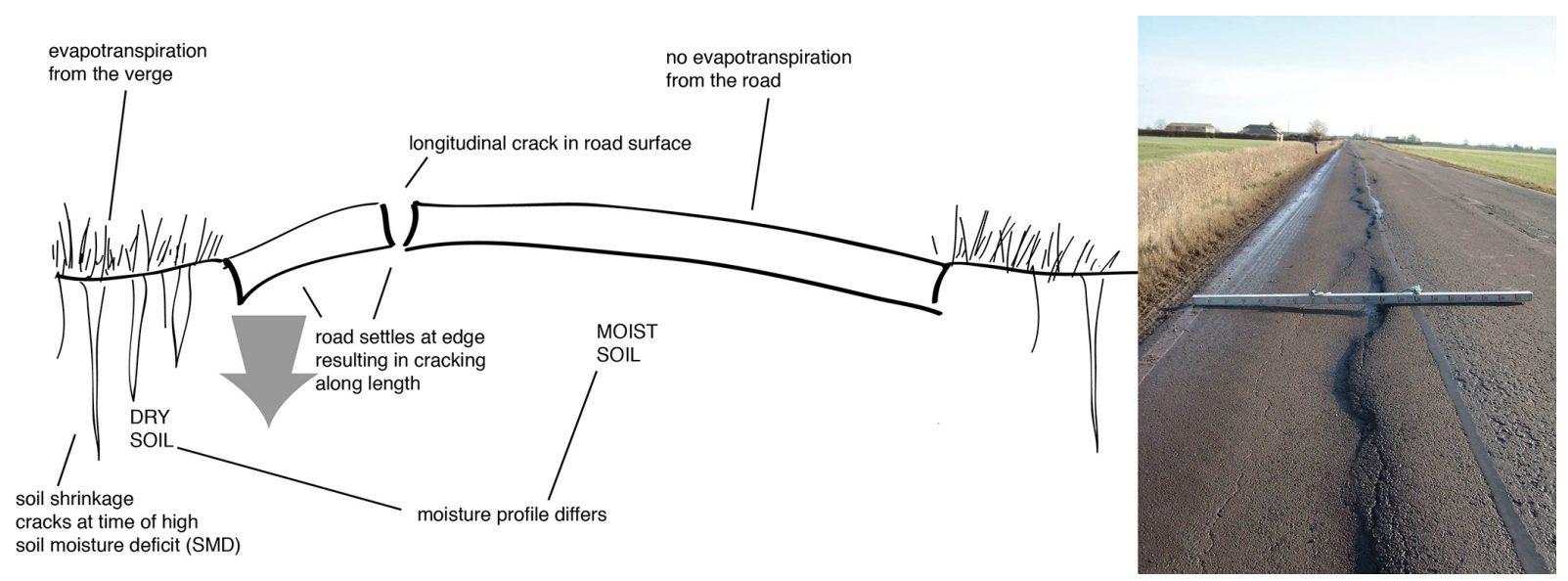

Figure 2. Soil processes leading to longitudinal cracking of road surface with photo example from Fodder Dyke, Lincolnshire (photo: Lincolnshire County Council, reproduced with permission; figure adapted from Pritchard et al., 2014, reproduced with permission).

- severe localised transverse depressions, which require drivers to slow to speeds below $20 \mathrm{mph}$;

- longitudinal differential settlement and cracking, requiring supplementary road signs to warn drivers and allow roads to remain open;

- defects which are not easily seen at night or in adverse weather conditions, increasing risk to motorists.

\section{Data}

\subsection{Natural Perils Directory (NPD)}

The NPD geohazard thematic data set, developed and maintained by staff at Cranfield University, provides a detailed and comprehensive assessment of the environmental vulnerabilities to building structures and infrastructure posed by soilrelated geohazards (Jones et al., 1995; Hallett et al., 1994). NPD represents a thematic reinterpretation of the national soil map (NATMAP) which shows the spatial distribution of all 700 soil series in England and Wales (Cranfield University, 2015). These soil data, alongside climatic data and expert knowledge, are encompassed within a Land Information System (LandIS) (Keay et al., 2009). LandIS is regarded as the principle source of soil information for England and Wales by Defra (Department for Environment, Food and Rural Affairs).

A core component of the NPD is the clay-related subsidence model, or the underground foundation stability (UFS) model. Based upon a pedoclimatic approach, UFS assesses the likelihood of a soil to undergo shrink-swell and subsequently, whether a potential soil moisture deficit (PSMD) is present for shrink-swell potential to be realised. Once classified, a 9 point vulnerability class, ranging from extremely high to extremely low is assigned. The NPD model output is expressed in a GIS (Geographical Information System) format on a vector polygon basis across England, Wales and Scotland. This makes it suitable for easy integration with other geospatial data (e.g. infrastructure networks). It is predominantly used by the insurance, reinsurance and water sectors. However, its use in highway asset management has not been explored until now.

\subsection{Highway condition data}

CVI assessment data for $\sim 4400 \mathrm{~km}(75 \%)$ of unclassified roads, collected between 2007 and 2014, were supplied in a GIS vector-polygon format by Lincolnshire County Council's highway department (M. Coates, personal communication, 2014). Data were supplied for four survey periods: 2007-2011, 2011-2012, 2012-2013 and 2013-2014. CVI is expressed as a series of indices, including assessments for wearing course, edge effects and structural condition. Following discussion with LCC, it was identified that the "structural condition index" provided the most suitable index for understanding the effects of soil on the network, which also incorporated edge defects. Conversely, wearing course degradation is a factor of traffic use, direct climatic effects and road surfacing techniques and therefore soils do not exert a direct effect.

Each structural condition index GIS vector polygon represented a $50 \mathrm{~m}$ rolling average survey area, where increasingly higher values indicated a worsening structural condition of the highway (P. Shevill, personal communication, 2014); values ranged between 0 and 93 . Generally, a value of $<40$ represents a road in a good state of repair, whereas values $>40$ require further investigation and likely treatment options. To avoid any potential survey bias, Lincolnshire is divided into 10 distinct sub-regional operational areas where a percentage of each of these areas is surveyed each year. Moreover, the current two-man surveying team, which has 
Table 3. CVI points assessed for each survey period per subsidence risk class.

\begin{tabular}{rrrrrrrrrr}
\hline & $\begin{array}{r}\text { Extremely } \\
\text { high }\end{array}$ & $\begin{array}{r}\text { Very } \\
\text { high }\end{array}$ & High & $\begin{array}{r}\text { Medium- } \\
\text { high }\end{array}$ & Medium & $\begin{array}{r}\text { Medium- } \\
\text { low }\end{array}$ & $\begin{array}{r}\text { Low } \\
\text { low }\end{array}$ & $\begin{array}{r}\text { Extremely } \\
\text { low }\end{array}$ \\
\hline $2007-2011$ & 3065 & 4976 & 1348 & 1544 & 4615 & 9 & 0 & 1249 & 11794 \\
$2011-2012$ & 3311 & 5237 & 1359 & 1577 & 4779 & 10 & 0 & 1340 & 12373 \\
$2012-2013$ & 3340 & 5483 & 1398 & 1588 & 4904 & 10 & 0 & 1360 & 12181 \\
$2013-2014$ & 3418 & 5367 & 1336 & 1541 & 4775 & 10 & 0 & 1323 & 11801 \\
\hline
\end{tabular}

undertaken the survey for a number of years, remains independent from maintenance scheme selection and is not influenced by budgetary constraints (M. Coates, personal communication, 2015).

\subsection{UKCP09 future climate projections}

UKCP09 climate projections (Jenkins et al., 2009) indicate that the UK is likely to experience hotter, drier summers and warmer wetter winters, especially in the south-east and east Anglian region of England, for the forthcoming century. Such weather patterns will exacerbate clay-related subsidence.

The long lifespan of road infrastructure in the UK leads to particular susceptibility to hazards under future climates (Willway et al., 2008). Research undertaken by the authors as part of the Infrastructure Transitions Research Consortium (www.itrc.org.uk) project has involved the modelling of probabilistic PSMD for the future scenarios of 2030 (20202049) and 2050 (2040-2069). Model parameters, daily rainfall and potential evapotranspiration (Eq. 1) were derived from a spatially coherent $5 \mathrm{~km}$ resolution gridded output from the UKCP09 weather generator (Burton et al., 2013; Jenkins et al., 2014).

$\mathrm{PSMD}=\sum($ rainfall - potential evapotranspiration $)$

PSMD represents the fundamental climatic control on clay-related subsidence and so has been incorporated within the NPD geohazard model (Pritchard et al., 2015). Future projections of clay subsidence risk for Lincolnshire are presented in Fig. 3. These enable assessment of future risk from ground movement for Lincolnshire's unclassified road network.

\section{Risk assessment}

\subsection{Overview}

We have determined statistically the relationship between CVI value and clay-subsidence risk class from NPD for each survey period. This section describes the GIS and statistical framework used to assess the impact of clay-related subsidence on Lincolnshire's unclassified road network, illustrated in Fig. 4. GIS software was employed to provide a platform for rapid analysis and handling of spatial data (Fedeski and Gwilliam, 2007), including CVI and clay subsidence risk class.

CVI data provided by LCC required processing to make the data suitable for intersection with the NPD data (Fig. 3). Polygon data were converted to points in ESRI's ArcGIS (v. 10.2) using the polygon centroid tools, and the opensource software, Geospatial Modelling Environment (www. spatialecology.com), was used to snap these points to the road section (vector line feature). Road sections (GIS format) for the entire Lincolnshire network, classified by road hierarchy, were provided by LCC. Processed CVI data were then intersected with the NPD geohazard data set and the resultant GIS shapefile attribute data imported directly into the statistical package, R (R Core Team, 2014), for further statistical analysis. The number of CVI points assessed per subsidence risk class are presented in Table 3. Similarly, future subsidence projections have been intersected with the Lincolnshire unclassified road network within the GIS in order to understand the change in potential exposure throughout these scenarios.

\section{Results}

\subsection{Current risk}

Our results suggest that a spatial and statistical relationship exists between clay-related subsidence risk and CVI (structural index) value. The box plots in Fig. 5 present the relationship between CVI over the survey periods of 2007-2011, 2011-2012, 2012-2013 and 2013-2014. Due to the extensive unclassified road network in Lincolnshire, a 4-year rolling CVI assessment program is used by the council. Therefore, each survey year often represents road sections different to those assessed in the previous year.

Ideally analysis would have considered many years/decades. However, the use of GIS in Lincolnshire's highway asset management remains a still-emerging technology. Prior to GIS techniques, CVI data recording was predominantly paper based and is therefore difficult to investigate alongside other environmental data.

Overall, the CVI structural index for Lincolnshire's unclassified network shows significant deterioration between the years 2007 and 2014. This is especially so on soils with an extremely high to high risk of clay-related subsidence, 


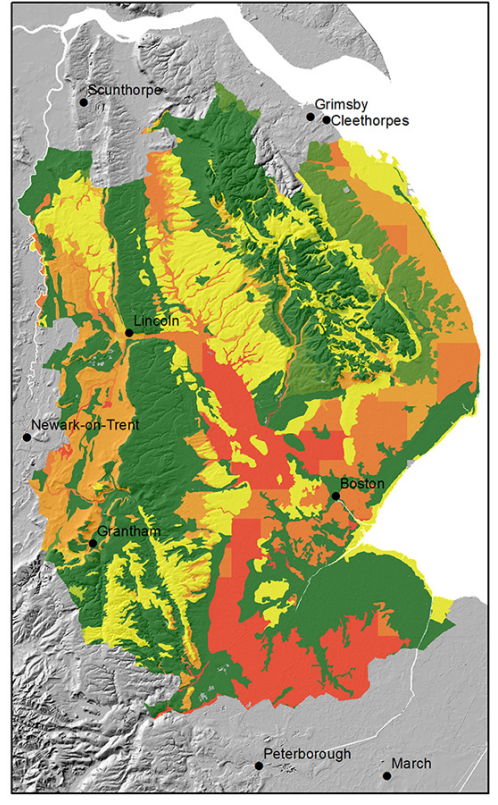

Baseline (1961-1990)

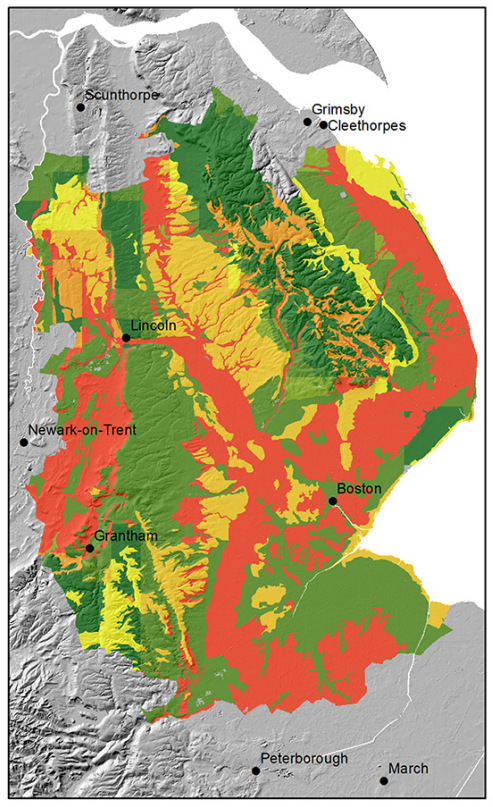

$2030(2020-2049)$

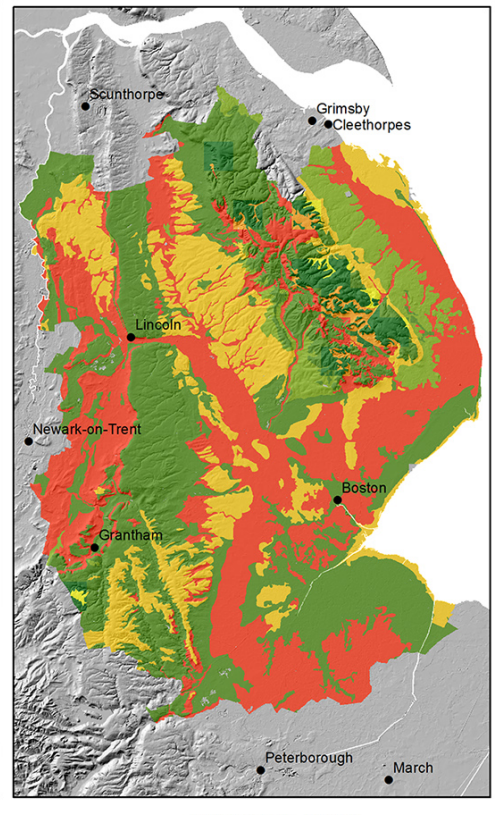

$2050(2040-2069)$

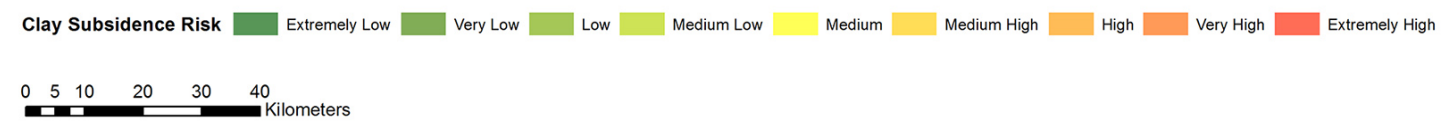

Figure 3. Modelled clay-subsidence risk at the central estimate (50th percentile) for baseline (1961-1990), 2030 (2020-2049) and 2050 (2040-2069) UKCP09 scenarios for the administrative county of Lincolnshire (contains Ordnance Survey data, Crown copyright and database right, 2015; soil data (England and Wales) ${ }^{\circledR}$ Cranfield University and for the controller of HMSO 2015).

where consistently high CVI values (i.e. $>60$ ) are observed, representing a significant deterioration of the structural road condition on these higher-risk soils; roads identified at current risk are provided in Fig. 6. Moreover, by 2012-2013 the CVI value on these soils has reached a critical point, whereby the roads are deemed to have failed structurally (i.e. CVI $>80$ ), resulting in the enforcement of speed restrictions as a result.

CVI for roads on soils at a medium-low risk for all survey periods showed a consistently high level of subsidence risk. However, this is only representative of a relatively low number of CVI points for each survey period $(9,10,10$ and 10). These values were therefore excluded from the analysis.

\subsection{Future risk}

The entire unclassified road network for Lincolnshire was intersected with future projections of clay subsidence risk for 2030 and 2050 (Fig. 3), using the 50th percentile or central estimate. From this, metrics were produced that identify lengths (kilometres) of road sections falling into each particular clay-related subsidence risk class. The resultant graph (Fig. 7) shows clear shifts of road sections into higher vulnerability classes from the baseline (1961-1990) through to 2050 (2040-2069). This is especially so for the extremely high class where between the baseline and 2050 there is a $\gtrsim 300 \%$ increase in the amount of road length on these soils. There is also a $\sim 1200 \%$ shift from roads being at a medium risk to those becoming at medium-high risk between baseline and 2030 and 2050 scenarios. However, medium-highrisk soils do not appear to exert such structurally damaging effects on road condition as compared with the higher classes (Fig. 5).

\section{Discussion}

The low traffic volumes on local road networks mean that the large capital investments required to adequately engineer all unclassified roads on highly shrinkable soils are an unaffordable solution in mitigating the impact of soil-related subsidence. Road deterioration is affected by a number of factors; however, this paper has shown quantitatively that clay-subsidence-prone soils exert a profound structural impact upon road conditions in the Lincolnshire study area. This has resulted in subsequent economic impacts, with calls made by the county for emergency funding from the DfT to clear the maintenance backlog.

ADEPT (2009) argue that climatic change may lead to wide-scale failure of the UK minor highway network. As 


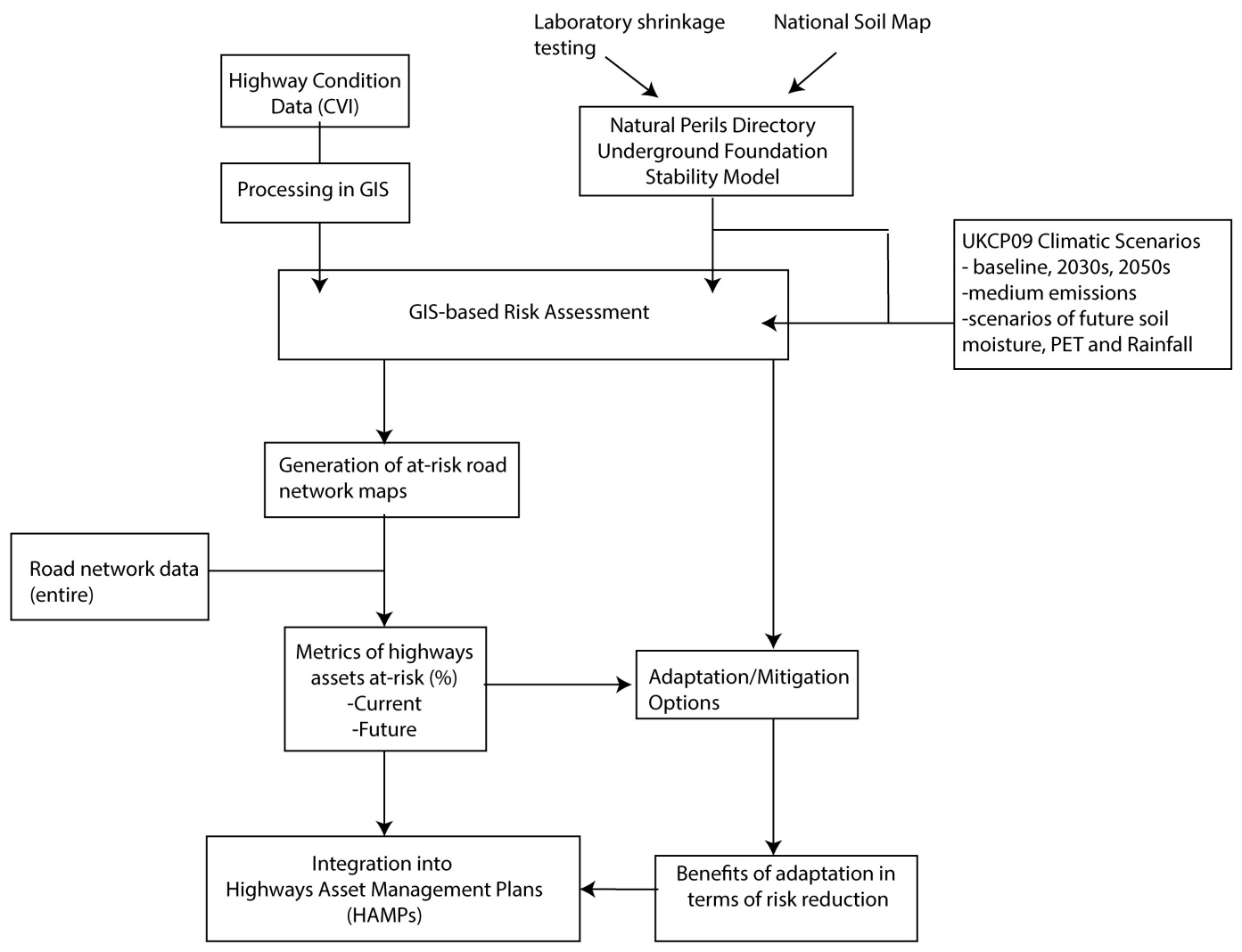

Figure 4. Conceptual risk-assessment framework for spatial clay subsidence risk impacts upon Lincolnshire road network.

Survey Period
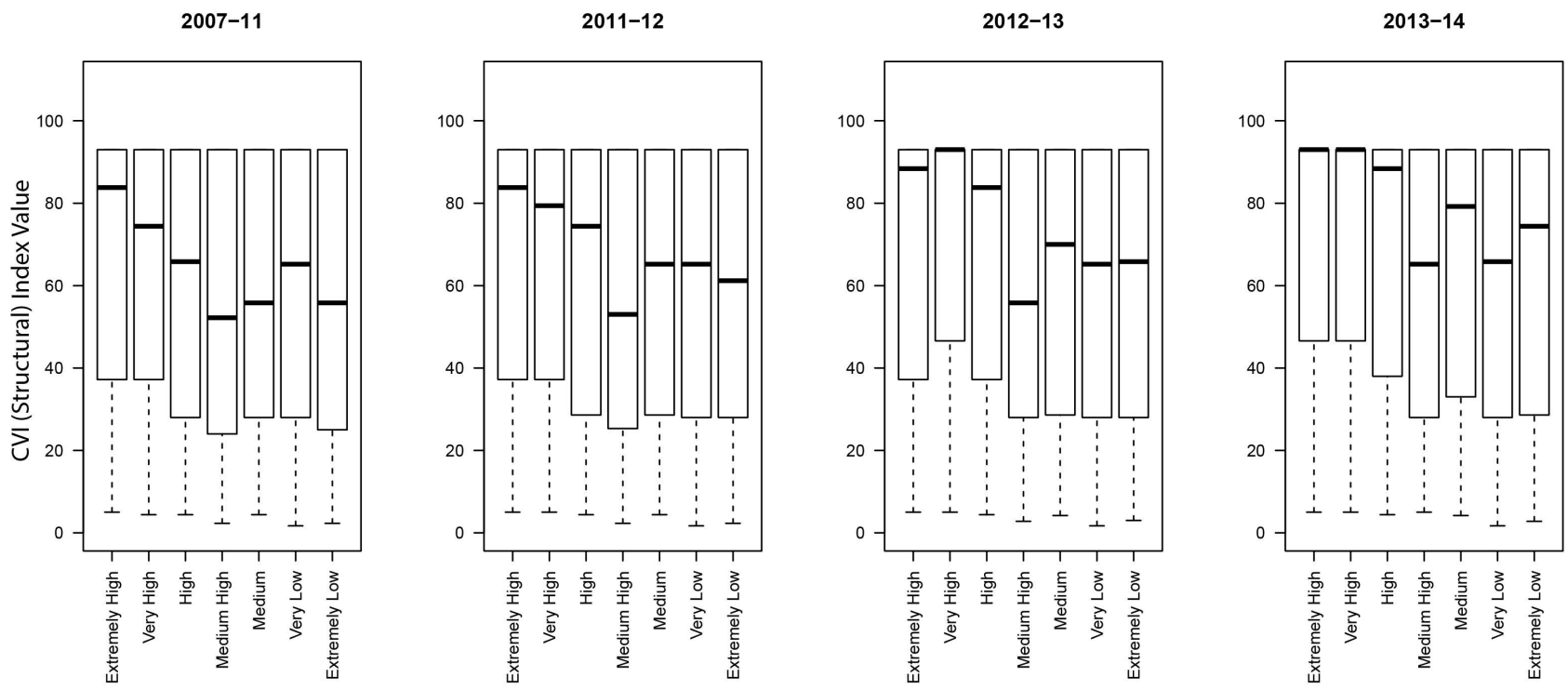

Clay Subsidence Risk Class

Figure 5. Clay subsidence risk against structural CVI (coarse visual inspection). 


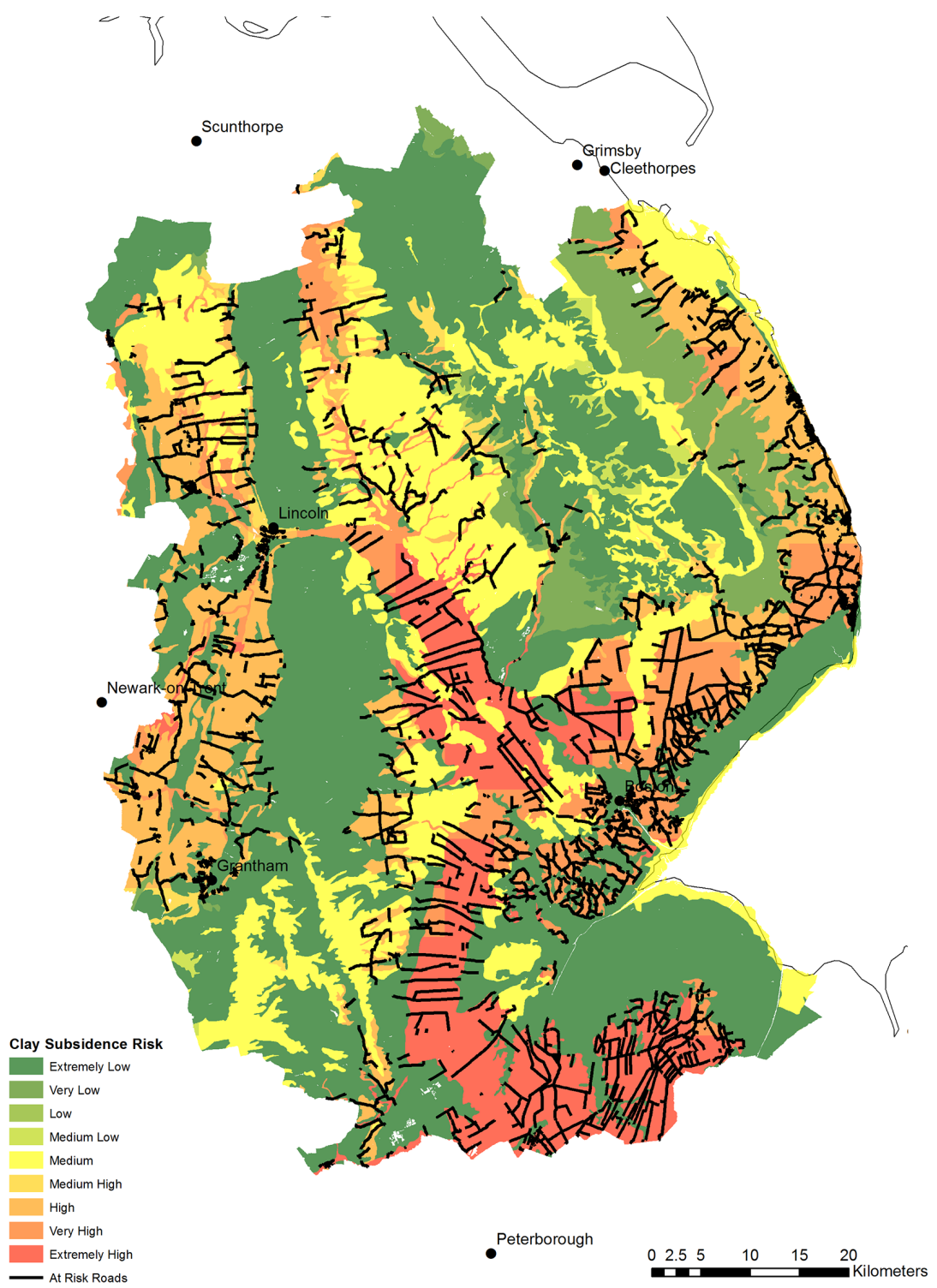

Figure 6. Road sections identified "at risk" of clay-related subsidence at present (soils data (England and Wales) ${ }^{\circledR}$ Cranfield University and for the controller of HMSO 2015).

this work shows, UKCP09 scenarios indicating hotter, drier summers and warmer, wetter winters through to 2080 (Jenkins et al., 2009) are likely to exacerbate clay-related subsidence risk (Harrison et al., 2012; Blenkinsop et al., 2010; Pritchard et al., 2015). Williams et al. (2012) argue that decisions around risk made by local authorities are predominantly a consequence of regulatory obligations. As a result, many studies have discussed the acute problem of flooding impact on highways, which causes widespread and economically significant damages (e.g. Bollinger et al., 2014). However, little attention has been brought to the impact of more chronic, systemic and less visible geohazards such as clayrelated subsidence to highway infrastructure. An analysis of the impacts of current and future geohazards to road infras- tructures nationally will lead to a greater awareness amongst local authorities and policymakers. It will also lead to a better understanding of the viable adaptation and mitigation options which can be implemented to tackle the issue at hand (Williams et al., 2012) as well as informing the debate on infrastructure investment planning.

The construction of entirely new roads in the UK is rare. More commonly, existing networks are upgraded (Brown, 2013). Rawlins et al. (2013) state that with new developments, an awareness of the potential hazards and the influence of climate change should be incorporated into design principles. As a result, the findings of this research can aid planning of new highways. 


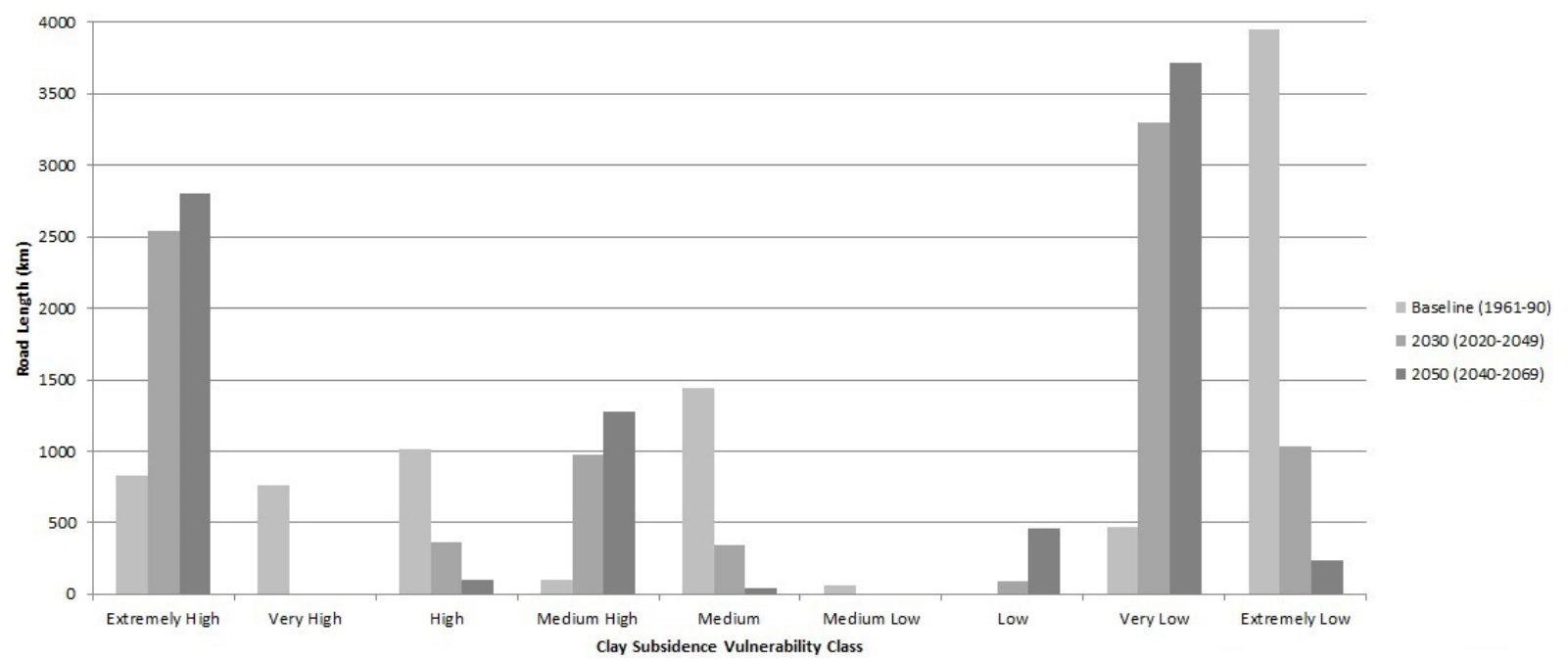

Figure 7. Road length kilometres per clay subsidence vulnerability class for baseline, 2030 and 2050 scenarios.

The All Party Parliamentary Group on Highway Maintenance recently called for the incorporation of highway asset management plans (HAMPs) within local authorities highway departments to become mandatory (APPGHM, 2013). Moreover, recommendations exist to make funding streams from the Department for Transport accessible only if HAMPs are in place. Therefore, specific risk information, in this case relating to the spatial distribution of hazardous soils, is vital to these asset management plans. Within LCC, integration of clay-related subsidence assessment within the planning of highway maintenance has provided the basis for a decisionsupport tool for establishing which specific treatments highway engineers can use to improve drought-damaged road sections. Whereas previously a blanket approach to resurfacing would have been applied to all affected sections, it is now recognised that unclassified road sections on droughtsusceptible soils are predominantly prone to failure. Therefore, with large capital investment not being an option, other value-for-money options are being sought.

LCC have made attempts to reinforce their road network, for example with the use of steel reinforcing grids (e.g. at A1073, Crowland) which act to reinforce the road structure on clay-subsidence-susceptible soils. Although this technique has proven successful, it is both expensive and proves problematic when resurfacing works or a utility trench has to be emplaced below the road surface, so it is not a wholly viable option. Moreover, Wanyan et al. (2015) state that thicker and stronger road surface layers do not necessarily provide better performance in respect to expansive clay soils but rather just delay inevitable cracking of the road surface. Instead, they posit that more attention should be focused on improving the stiffness and strength of the roads foundation (or subgrade).

More recently, LCC have been trialling an in situ road recycling process known as retread, for specific drought- affected sections of their network. This process involves the re-incorporation of in situ road planings into the foundation of the road. Retread offers an in situ treatment using cold-laying techniques; therefore heat and more energy is not required (Heaton, 2014). Being in situ, this also reduces the high disposal costs of potentially hazardous (bitumencontaining) waste to landfill. Moreover, road planings acquired from other sites across the network have been imported in some areas to further deepen road foundations to try and minimise the impacts of clay-related subsidence.

A sum of $£ 1$ million, within the Lincolnshire road maintenance budget, has been sourced from a bid to central government and assigned to the retread project over the period 2013-2015. This process, although having been implemented in other counties for a number of years, is a new initiative by LCC. Due to this approach being novel in Lincolnshire, it is not currently known what the long-term reliability of this method will be on Lincolnshire's subsidenceprone soils; however, current results appear positive (Heaton, 2014).

Although not explored within this paper, the shrinkage of clay soils is a known precursor to shallow and deep-seated slope movements (Page, 1998). In this situation, shrinkage cracks allow water ingress to reach clay shear surfaces (Loveridge et al., 2010). This results in increased pore-water pressures, especially during intense storms. High pore-water pressure with additional weight from large agricultural vehicles or articulated delivery vehicles can result in shear slippage, slope movement and subsequent highway failure (Hawkins, 2013; Loveridge et al., 2010). As a result of agricultural and drainage practices, much of the highway network in Lincolnshire is flanked by steep-sided drainage dikes or has been left raised above the surrounding land due to peat shrinkage. Therefore, these steep-sided embankments 


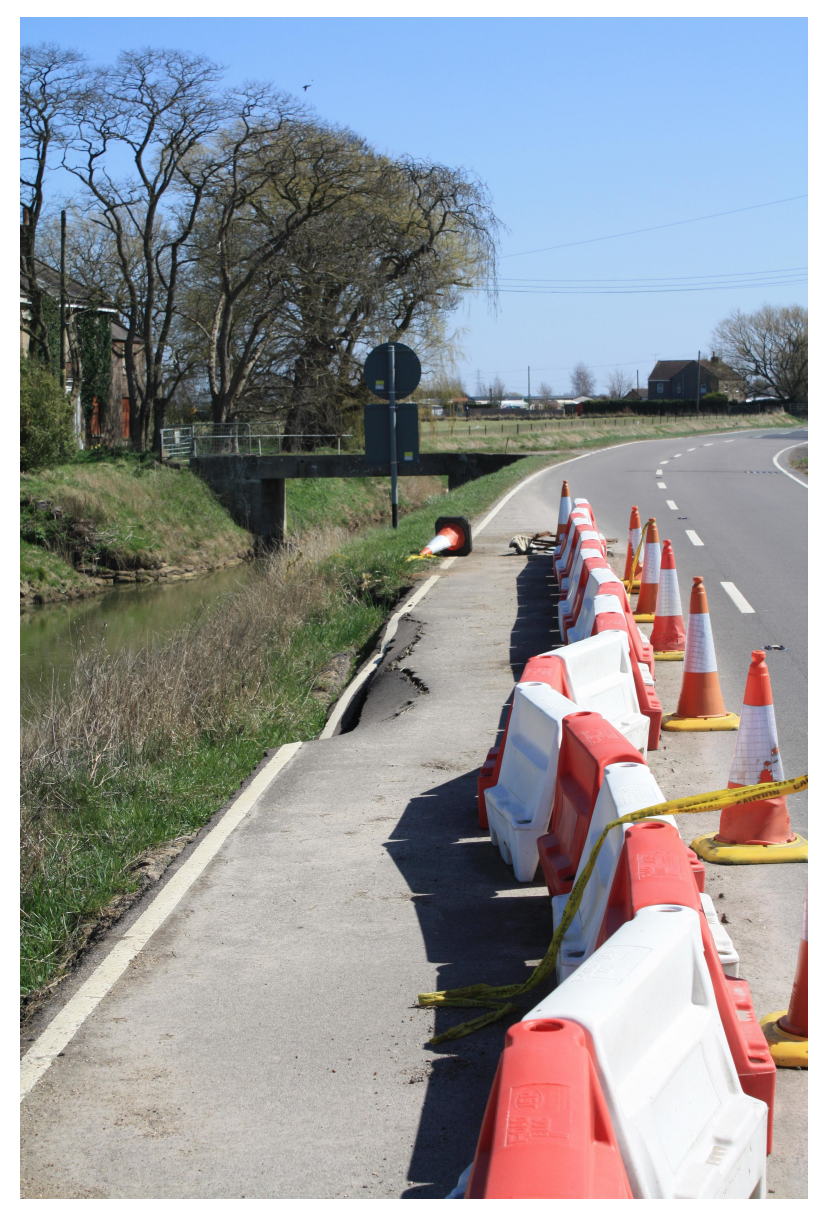

Figure 8. Road embankment instability, B1165 Ravens Bank, Lincolnshire (photo: O. Pritchard).

and the presence of shrink-swell soils can lead to specific localised slope failure (e.g. Fig. 8).

This paper has assessed the use of soil-related geohazard mapping in the asset management of minor highway networks within Lincolnshire. The risk-assessment framework (Fig. 4) presented has enabled LCC to prioritise its limited road maintenance capital on road sections at risk from drought-related clay subsidence. It has also acted as the basis for a decision-support tool, making highway engineers more conscious as to where hazardous soils present themselves spatially, highlighting the damaging effect that these can have upon the unclassified road network during drought conditions as well as guidance as to which treatments prove economically and structurally viable.

The study also highlights the structurally damaging effects that are likely to occur on England's unclassified road network under the UKCP09 climate projections and on soils prone to clay-related subsidence, especially in the south-east of England. The incorporation of probabilistic subsidence projections provides a novel approach to evaluate the future risk of soils to highway networks. The standardised CVI method of road condition survey within the UK means that rapid soil-geohazard assessment could be readily applied to other administrative areas affected. Further research is required to consider the potential impacts of other infrastructure failures and maintenance activities (e.g. water main failures and construction of utility trenches) on the soil structure and to what extent this results in degradation of road foundations and ultimately of road surface quality.

\section{Conclusions}

This research has considered the impact of clay-related subsidence on highways from a UK perspective. The issue of the impact of expansive soil on road surface conditions, however, is a recognised problem for a number of countries. The soil-informed maintenance strategy proposed here could be extended and applied successfully in an international context, highlighting the inherent value in a greater cooperation between highway engineers and engineering geologists, geomorphologists and soil scientists; highway engineers often having little earth-science experience. This strategy also enables the incorporation of modelled climate change impacts, which, with global scenarios, indicate an increased vulnerability of global infrastructure networks as a result. Therefore any improvement on climate adaptation measures is highly beneficial for the continuous and economical running of highway networks globally. The availability of appropriate soil data (e.g. national soil survey maps) and empirically derived shrink-swell assessment will often dictate the potential of the methodology presented here. However, the recently launched SMOS (Soil Moisture and Ocean Salinity) and SMAP (Soil Moisture Active Passive) satellite platforms provide tools to obtain almost real-time data to predict soil moisture levels in areas where meteorological data are sparse and to predict potentially damaging impacts on highway infrastructure where expansive soil distribution is known. Moreover, differential SAR interferometry, which is able to detect ground movements at the millimetre scale (Calo et al., 2014), could be a source of estimating where expansive soils are distributed, importantly providing a more economical means to undertake regional, national-scale and even cross-border assessments of shrink-swell impacts on road infrastructure.

Acknowledgements. The research reported in this paper was part of the UK Infrastructure Transitions Research Consortium (ITRC), funded by the Engineering and Physical Sciences Research Council under programme grant EP/I01344X/1. The research also received support from Cranfield University's EPSRC-funded Impact Accelereation Account (EP/K503927/1). The authors are grateful to Mike Coates, Mark Heaton, Matt Huddlestone and Phil Shevill at Lincolnshire County Council Highways for data contributions and for providing highway engineering expertise. 
Edited by: P. Tarolli

Reviewed by: two anonymous referees

\section{References}

Abam, T. K. S., Ofoegbu, C. O., Osadebe, C. C., and Gobo, A. E.: Impact of hydrology on the Port-Harcourt-Patani-Warri Road. Environ. Geol., 40, 153-162, 2000.

ADEPT (Association of Directors of Environment, Economy, Planning and Transport), Climate change and evolved pavements, available at: http://www.climatesoutheast.org.uk/images/ uploads/Climate_Change_and_evolved_pavements.pdf, 2009.

Alexander, W. S. and Maxwell, J. Controlling shrinkage cracking from expansive clay sub-grades, in: Reflective cracking in pavements, edited by: Fracken, L., Beuving, E., and Molenaar, A. A. A., E and FN Spon, London, 1996.

Allemeier, K.: Application of pedological surveys to highway engineering in Michigan, in: Non agriculatural application of soil surveys: Developments in Soil Science 4, edited by: Simonson, R., Amsterdam, Elsevier, 87-98, 1974.

APPGHM (All Parliamentary Group on Highway Maintenance).: Managing a valuable asset: improving local road condition, available at: http://www.highwaysmaintenance.org/images/library/ files/APPG_Report_-_Managing_a_valuable_asset.pdf, 2013.

Astbury, A. K: The Black Fens, The Golden Head Press Ltd, Cambridge, 1958.

Bauer, K. W.: The use of soils data in regional planning, Geoderma, 10, 1-26, 1973.

Beatty, M. T. and Bouma, J.: Application of soil surveys to selection of sites for on-site disposal of liquid household wastes, Geoderma, 10, 113-122, 1973.

Biggs, A. and Mahony, K: Is soil science relevant to raod infrastructure?, 13th International Soil Conservation Organisation Conference, Conserving soil and water for society: Sharing solutions, Brisbane, ISCO, 2004.

Blenkinsop, S., Hallett, S., Truckell, I., and Fowler, H.: The CREW project: Towards a toolkit for the use of probabilistic climate change projections, BHS Third International Symposium, Role of Hydrology in Managing Consequences of a Changing Global Environment, 1-8, 2010.

Bollinger, L. A., Bogmans, C. W. J., Chappin, E. J. L., Dijkema, G. P. J., Huibretgse, J. N., Maas, N., Schenk, T., Snelder, M., van Thienen, P., de Wit, S., Wols, B., and Tavasszy, L. A.:. Climate adaptation of interconnected infrastructures: a framework for supporting governance, Reg. Environ. Change, 14, 919-931, 2014.

Brown, S. F.: An introduction to asphalt pavement design in the UK. Proc. Inst. Civ. Eng. Transp., 166, 1-14, 2012.

Burton, A., Glenis, V., Jones, M. R., and Kilsby, C. G.: Models of daily rainfall cross-correlation for the United Kingdom, Environ. Modell. Software, 49, 22-33, 2013.

Burton, R. and Hodgson, J.: Lowland peat in England and Wales, Harpenden, Soil Survey of England and Wales, 1987.

Calo, F., Ardizzone, F., Castaldo, R., Lollino, P., Tizzani, P., Guzzetti, F., Lanari, R., Angeli, M., Pontoni, F., and Manunta, M.: Enhanced landslide investigations througgh advanced DInSAR techniques: The Ivancich case study, Assisi, Italy, Remote Sens. Environ., 142, 69-82, 2014.
Chatwin, C. P.: British Regional Geology: East Anglia and adjoining areas; Fourth Edition. Her Majesty's Stationery Office, London, 1961.

Cranfield University: National Digital Soil Map 1 : 250000 scale (NATMAP), NATMAPvector, available at: http://www.landis. org.uk/data/natmap.cfm, 14 September 2015.

Dafalla, M. and Shamrani, M. A.: Road damage due to expansive soils: Survey of the phenomenon and measures for improvement, in: Design, construction, rehabilitation, and maintenance of bridges, edited by: Moyo, P., Ooi, P., Zhai, E., and Myers, J., Geohunan, China, 73-80, 2011.

Defra (Department for the Environment, Food and Rural Affairs): The National Adaptation Programme: Making the country resilient to a changing climate, The Stationery Office, London, available at: https://www.gov.uk/government/uploads/system/ uploads/attachment_data/file/209866/pb13942-nap-20130701. pdf, 2013.

DfT (Department for Transport): Road Network Policy Consultation, London, available at: https://www.gov.uk/ government/uploads/system/uploads/attachment_data/file/2439/ roadnetworkconsultation.pdf, 2011.

DfT (Department for Transport): Guidance on Road Classification and the Primary Route Network, London, available at: http://www.thensg.org.uk/documents/Guidance_on_Road_ Classification_and_Primary_Route_Network.pdf, 2012.

Fedeski, M. and Gwilliam, J.:. Urban sustainability in the presence of flood and geological hazards: The development of a GIS-based vulnerability and risk assessment methodology, Landscape Urban Plan, 83, 50-61, 2007.

Hallett, S. H., Keay, C., Jarvis, M., and Jones, R. J. A.: INSURE: Subsidence risk assessment from soil and climate data, in: Proceedings of the Association for Geographic Information (AGI) National Conference: Markets for Geographic Information, Assoc. Geogr. Inform., 16.2.1-16.2.7, 1994.

Harrison, A. M., Plim, J. F. M., Harrison, M., Jones, L. D., and Culshaw, M. G.: The relationship between shrink-swell occurrence and climate in south-east England, Proc. Geol. Assoc., 123, 556575, 2012.

Hartnup, R. and Jarvis, M.: Soils in Civil Engineering and Planning, in: Soil Survey Applications, edited by: Jarvis, M. and Mackney, D., Harpenden, Soil Survey, Technical Monograph No. 13, 110 134, 1979

Hawkins, A.: Some engineering geological effects of drought: examples from the UK, Bull. Eng. Geol. Environ., 72, 37-59, 2013.

Heaton, M.: Case Studies: Carriageway Retread in Lincolnshire 2013-14, Asphalt Professional, available at: http://www.instituteofasphalt.org/index.php?id=asprooverview (10 February 2015), 2014.

Hodge, C. A. H., Burton, R. G. O., Corbett, W. M., Evans, R., and Seale, R. S.: Soils and their use in Eastern England, Harpenden, Soil Survey of England and Wales, 13, 1984.

Hough, M. N. and Jones, R. J. A.: The United Kingdom Meteorological Office rainfall and evaporation calculation system: MORECS version 2.0 - an overview, Hydrol. Earth Syst. Sci., 1, 227-239, doi:10.5194/hess-1-227-1997, 1997.

ICE (Institution of Civil Engineers): The State of the Nation: Infrastructure 2014, London, available at:. http: //www.ice.org.uk/Information-resources/Document-Library/ 
State-of-the-Nation--Infrastructure-2014 (14 September 2015), 2014.

Jegede, G.: Effect of soil properties on pavement failures along the F209 highway at Ado-Etki, south-western Nigeria, Constr. Build. Mater., 14, 311-315, 2000.

Jenkins, G., Murphy, J., Sexton, D., Lowe, J., Jones, P., and Kilsby, C.: UK Climate Projections: Briefing Report, Met Office, Exeter, available at: http://ukclimateprojections.metoffice.gov.uk/media. jsp?mediaid=87867andfiletype=pdf, 2009.

Jenkins, K., Hall, J., Glenis, V., Kilsby, C., McCarthy, M., Goodess, C., Smith, D., Malleson, N., and Birkin, M.: Probabilistic spatial risk assessment of heat impacts and adaptations for London, Climate Change, 124, 105-117, 2014.

Jones, R. J. A., Hallett, S., Gibbons, J., and Jarvis, M. G.: Subsidence risk - using a complex dataset to identify areas most at risk, in: Proceedings of the Association for Geographic Information (AGI) National Conference: Insurance, Assoc. Geogr. Inform., 2.4.1-2.4.7, 1995.

Keay, C. A., Hallett, S. H., Farewell, T. S., Rayner, A. P., and Jones, R. J. A.: Moving the National Soil Database for England and Wales (LandIS) towards INSPIRE Compliance, Int. J. Spat. Data Infrastruct. Res., 4, 134-155, 2009.

Lee, E. and Griffiths, J.: The importance of pedological soil survey in land use planning, resource assessment and site investigation, in: Planning and Engineering Geology, edited by: Culshaw, M., Bell, F. G., Cripps, J. C., and O'Hara, M., Geological Society of London, London, 453-465, 1987.

Loveridge, F. A., Spink, T. W., O’Brien, A. S., Briggs, K. M., and Butcher, D.: The impact of climate and climate change on infrastructure slopes, with particular reference to southern England, Q. J. Eng. Geol. Hydrogeol., 43, 461-472, 2010.

Murtha, G. and Reid, R.: Soils of the Townsville area in relation to urban development, CSIRO Australia, Division of soils, Divisional report No. 11, available at: https://publications.csiro.au/rpr/pub?list=BROandpid=procite: 6a36119d-65e2-4786-a73e-3985057ea5a9 (14 September 2015), 1976.

Page, R.: Reducing the cost of subsidence damage despite global warming, Struct. Surv., 16, 67-75, 1998.

Pritchard, O. G., Hallett, S. H., and Farewell, T. S.: Soil impacts on UK infrastructure: current and future climate, Proc. Inst. Civ. Eng. Eng. Sus., 167, 170-184, 2014.

Pritchard, O. G., Hallett, S. H., and Farewell, T. S. Probabilistic soil moisture projections to assess Great Britain's future clay-related subsidence hazard, Climatic Change, doi:10.1007/s10584-0151486-z, 2015.
Puppala, A. J., Manosuthkij, T., Nazarian, S., and Hoyos, L. R.: Threshold moisture content and matric suction potentials in expansive clays prior to inititation of cracking in pavements, Can. Geotechnol. J., 48, 519-531, 2011.

R Development Core Team: A language and environment for statistical computing, R Foundation for Statistical Computing, Vienna, Austria, http://www.R-project.org/ (14 September 2015), 2014.

Rawlins, B. G., Harris, J., Price, S., and Bartlett, M.: A review of climate change impacts on urban soil functions with examples and policy insights from England, UK, Soil Use Manage., doi:10.1111/sum.12079, 2013.

Robson, J.: Soils of Boston and the Spalding District, Soil Survey and Land Research Centre, Silsoe, UK, 1990.

Royse, K. R.: The handling of hazard data on a national scale?: a case study from the British Geological Survey, Surv. Geophys., 32, 753-776, 2011.

Santi, P. M. and Martens, J. L.: Engineering Soils Maps, Environ. Eng. Geosci., 9, 179-183, 2003.

Sapkota, B., Nakamura, T., and Kiriyama, T.: Response of thin seal coated road pavement to the swelling and shrinking of reactive clay subgrades, J. Mater. Conc. Struct. Pavements, 557, 111-120, 1997.

Wallis, J.: The UKPMS User Manual. Volume 2: Visual data collection for UKPMS. Chapter 7: Coarse Visual Inspection (CVI), available at: http://www.pcis.org. uk/iimni/UserFiles/Applications/Documents/Downloads/ UKPMSManualsandGuides/Manual/UKPMSManual_02_ 07v09.pdf, 2009.

Wanyan, Y., Abdallah, I., Nazarian, S., and Puppala, A. J.: Moisture content-based longitudinal cracking prediction and evaluation model for low-volume roads over expansive soils, J. Mater Civil Eng., doi:10.1061/(ASCE)MT.1943-5533.0001217, 2014.

Westerveld, G. J. W. and Van Den Hurk, J. A.: Application of soil and interpretive maps to non-agricultural land use in the Netherlands, Geoderma, 10, 47-65, 1973.

Williams, K., Joynt, J. L. R., Payne, C., Hopkins, D., and Smith, I.: The conditions for, and challenges of, adapting England's suburbs for climate change, Build. Environ., 55, 131-140, 2012.

Willway, T., Reeves, S., and Baldachin, L.: Maintaining pavements in a changing climate, Department for Transport/Transport Research Laboratory, London, available at: http://www.ukroadsliaisongroup.org/download.cfm/docid/

77CBE77B-93A4-4D1D-B9782B47987990C1 (14 September 2015), 2008.

Zumrawi, M. M. E.: Geotechnical aspects for roads on expansive soils, Internat. J. Sci. Res., 4, 896-902, 2015. 